\title{
Experimental Investigation of Segregation of Granular Materials using the Vibrational Phenomenon
}

\author{
${ }^{1}$ K. T. Aminu, ${ }^{1}$ M. M. Jibril, ${ }^{2}$ S.D. Bashir \& ${ }^{1}$ A. G. Jumba \\ ${ }^{1}$ Department of Electrical Engineering, Abubakar Tatari Ali Polytechnic, Bauchi, Nigeria \\ ${ }^{2}$ Department of Mechanical Engineering, Abubakar Tatari Ali Polytechnic, Bauchi, Nigeria
}

\begin{abstract}
Many industrial processes including food, mining, material and pharmaceuticals involve the handling of granular materials. The tendency of granular materials to segregate due to variation of certain parameters as well as differences in particle properties such as size, density, shape negatively affect the process efficiency and product quality. In this study, the segregation phenomena of different large particles in a granular bed were studied experimentally in a Perspex box that was vibrated vertically. In particular, the effect of frequency, bed depth, particle size and density were investigated. The result showed that the segregation at relatively constant acceleration was found to decrease within the frequency range $20 \mathrm{~Hz}-40 \mathrm{~Hz}$. On the other hand, the segregation then increases with increasing frequency. Furthermore, within the same frequency range, segregation was observed to further decrease with increasing acceleration, and then gradually starts decreasing exponentially with frequency. In addition, the segregation rate was higher at a greater bed depth for all vibratory conditions. The segregation trend was found to increase with the size of the particles for all vibratory conditions. Nonetheless, for all vibratory conditions, the segregation rate was lower for intruder particles with higher density.
\end{abstract}

Key words: Density, Intruder Particle, Acceleration, Granular Materials, Segregation, Convection Vibration.

\section{INTRODUCTION}

According to Roskilly, S. J et. al., "particle segregation is important in many industries, including the important case of pharmaceutical formulations where segregation can cause poor content uniformity and result in subsequent batch rejection" [1]. Segregation occurs when a granular material placed in a container are vibrated vertically or horizontally. A further definition of segregation is given by Hogg, $\mathrm{R}$, who describes it as a consequence of the differences in the basic particle properties [2]. These properties can be defined in terms of structure, size, shape and composition.

For many years, several studies have demonstrated some of the significant features associated with segregation of granular materials due to vibration. The study by Rosato, A. D et. al., experimentally examined the influence of vibration frequency on the movement of a single large sphere in a granular bed (consisting of sand) that was vibrated vertically [3]. The most obvious finding to emerge from the experiments is that the single large particle was always observed to rise to the top. A possible explanation for this might be that the small sand grains below the large sphere particle are stationery thus preventing it from falling, while the fine grains at the side and top being free to move. Hence, while the large single particle experiences upward movement during vibration, the small particles were observed to flow underneath. This causes the large particle to ascend to the top. This finding broadly supports the work of [4] on why the Brazil nuts are on top. Subsequently, Rosato, A. D et. al., proposes that elasticity, density, size, shape are the critical particle characteristics that influence segregation [3]. In addition the work also identifies the mechanisms of segregation: percolation fines, trajectory segregation and the rise of coarse particles due to vibration [5].

Based on detailed experimental work of Rosato, A. D et. al., proposed that the geometrical mechanism was responsible for the size separation in a vibrated granular medium [4]. The Mote Carlo (MC) simulation technique was adapted and used in statistical physics to indicate that local geometrical void filling can result to size segregation with larger particles. Knight, J. B et. al., suggested that segregation is driven by convection [6]. The finding confirmed that boundaries can significantly influence on segregation. It simply seems that the frictional collision of sand particles with the side walls can set up convection enough to cause the large particles to even go to the bottom as determined by the shape of the container. Majid, M. \& Walzel, P, performed similar series of experiments and observed that "by tilting the side walls of the container outwards, the direction of the convection cells can be reversed" [7]. In a study investigating the transition between normal and reversal convection rolls, [7] scrutinized the 
force experienced by the particles close to the walls by preparing walls of different roughness. The study found that "the smoother walls enhance reverse rolls while the rougher walls produce strong normal rolls". Moreover, in a study which set out to determine of container geometry on granular segregation pattern due to vibration in a set of quasi-two-dimensional container, [8] found that depending on the bending degree, three segregation patterns were identified: Two side-segregation pattern, a left-hand side segregation pattern and a pattern where the big particles aggregate to the upper left part of the container.

A considerable amount of literature has been published on the physical mechanisms that affect the phenomenon of segregation in vibrated granular beds. [9] examined segregation by size of two-dimensional grains in vibrated granular beds using the particle dynamics method and investigate the influence of convection and friction between particles on the segregation. In the work, the authors utilised the dynamic model developed by Elperin, T [9]. Elperin, T et. al., have been able to study the motion (both rotational and transitional) of individual molecules using the solution of Newtonian equations of motion. The result from the study indicated that "the rate of segregation increases when the coefficient of friction increases and it becomes quite high with the appearance of the convective rolls". The conclusion was that "the segregation with low segregation rate is associated with the relative particles motion and appear also in the case of frictionless particles and segregation with high segregation rate is associated with the onset of convective motion and appears only when the coefficient of friction particles exceeds some threshold $\mu_{\mathrm{o}}\left(\mu_{\mathrm{o}} \approx 0.4\right.$ in the study). To better understand the mechanisms of segregation and its effects DŽiugys, A. et. al., use the discrete element model (DEM) to analyse the process of mixing and size segregation in polydisperse mixture of spherical particles in a three-dimensional rectangular box [10]. The influence of friction between the particles on segregation was also analysed in the study. In their seminal work, several researchers have investigated the mechanism of friction and its effect on segregation [10].

A significant study on the effects of air and discussion on its influence upon the motion of the intruder particle was presented by [11-12]. The effect of interstitial air was first demonstrated experimentally by [11]. Particularly, for a large particle in a granular bed that is vibrated vertically, the study found that the intruder may sink or rise depending on the size and density variation of the intruder in the presence of interstitial air. In addition, MÖbius, M. E et. al., employs high speed video and magnetic resonance imaging (MRI) to investigate the movement of a large sphere in a vertically vibrated bed of small sand particles [12]. The finding indicated a non-monotonic density dependence of the sink and rise time for the large sphere in air-driven size segregation. "At relatively high density, the rise was faster for light and heavy particles".

Detailed examination of the effects of vibration frequency on intruder's position in granular bed utilising molecular dynamic simulations by Kong, $\mathrm{X}$ et. al showed that at fixed acceleration and variable frequency of vibration, big particles move upwards towards the centre as if they seep through the assembly and move up again and stay at certain height of the granular bed at relatively low and sufficiently high frequency respectively [13]. In addition, Ahmad, K et. al., have demonstrated experimentally through the application of simulation model of granular segregation in a fixed wall cylinder [14]. In their seminal study, they observed that, large particles remain staying on the bottom of the container; move upwards and stay on the top of the granular bed; at high vibration frequency and dive deeply back into the granular bed at low, intermediate and high frequencies of vibration respectively. These results from the simulations further showed the complicacy of granular segregation due to vibration. It could be concluded from their study that the most important parameter influencing segregation appears to be the frequency of vibration.

The effects of acceleration and vibration frequency on the rise time of a single large particle in vibrated granular bed formed the central focus of a study by Ahmad, K et. al., in which the authors found several important characteristics that are worthy of note. These findings revealed that at constant frequency of vibration, the rise time was observed to decrease with increasing acceleration and at constant acceleration, the rise time was observed to increase with increase in frequency within a certain range. In addition, at higher frequency the rise time has increased within the same range of acceleration. The present results are significant in at least one major respect: the acceleration seems to be a crucial parameter in controlling the segregation of large particles within a certain range of frequency. However, the findings of the study revealed that size and density effects were dominant and that the shape of the large particle of the same mass may not have significant effect on the segregation rate of the particle. Nevertheless, however, the work of [3] systematically studied the influence of vibration amplitude and frequency in an experiment involving radioactive tracer powders. The significance of particle characteristics as well as vibration amplitude and frequency on the segregation mechanism were noticed. This also corroborated the view of [14]

Considering all of these evidences, this paper will focus on investigating the mechanism of segregation under harmonic excitation subjected to different granular bed depth. Moreover, the influence of particle characteristics will also be examined.

\section{SYSTEM DESCRIPTION}

The experimental setup used in the study was LabVIEW- based. The important components of the setup include a Perspex box, air-cooled vibration exciter (LDS V455), LDS PA 1000L amplifier and accelerometer. The Perspex box was mounted externally 
on LDS V455 plate via the spacer and using bolt and nut $6 \mathrm{~mm}$ in size and is used to generate the sine vector force. The LDS V455 is placed on an isolator platform to prevent interfering signals from nearby environment. The LDS V455 is driven through a 1400 VA, LDS PA 1000L amplifier. The LDS PA 1000L amplifies the signal of 400mV amplitude from the sine square oscillator at the selected test frequency. Accelerometer installed on the base plate captures the acceleration signal. It is recommended that the mounting location should be clean and paint free and the mounting should be spot-faced. The spot-faced diameter should be slightly larger than the accelerometer diameter. In order to prevent the vibrator from generating excessive heat, a cooling fan is connected to the vibrator. Figure 1 shows the LabVIEW- based experimental setup.

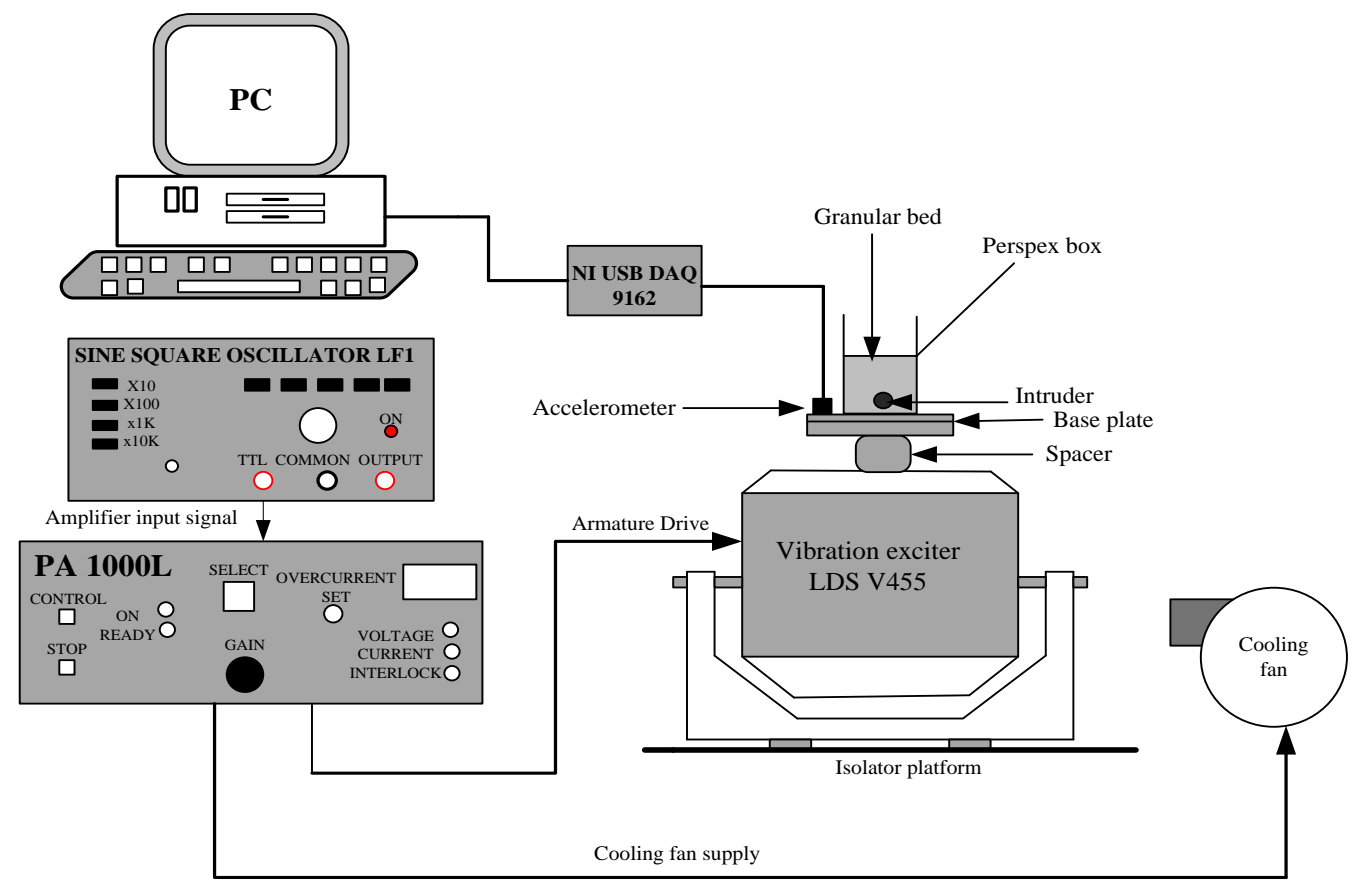

Figure 1 Schematic diagram of the LabVIEW- based experimental se up

Data acquisition was achieved by an accelerometer connected to the PC via NI USB-9162 data acquisition (DAQ) card. The operation of the DAQ is controlled with the LabVIEW 8.5 software. All relevant VI's for the vibration level measurement and the elapsed time VI that counts the time once the LabVIEW program has started running are available in the software. Adjusting the gain control knob of the PA 1000L amplifier can give the acceleration magnitude desired for the test run and this can be monitored by the LabVIEW program.

\section{METHODOLOGY}

A series of experimental tests were conducted using the setup shown in Figure 1. Prior to the commencement of each experimental run, carefully, the intruder particle was placed at the bottom centre of the Perspex box filled with dry sand to a height of $75 \mathrm{~mm}, 100 \mathrm{~mm}$ and $125 \mathrm{~mm}$ respectively. The Perspex box was vibrated with a sinusoidal signal at a of level of $0.4 \mathrm{~V}$ peak to peak using the signal generator over a range of frequencies from $20 \mathrm{~Hz}$ to $100 \mathrm{~Hz}$ in the vertical direction with a fixed acceleration of $4 \mathrm{~g}$ and $5 \mathrm{~g}$ respectfully. In addition, the was kept constant at the value of $40 \mathrm{~Hz}, 60 \mathrm{~Hz}$ and $80 \mathrm{~Hz}$ with the acceleration varying in the range $3 \mathrm{~g}$ to $7 \mathrm{~g}$. The accelerometer was precise and independent of its structural resonance at these of frequencies. The application of the vibration to the Perspex box was made concurrently with the running of the LabVIEW program and the stop watch counter. The movement of the intruder particle in the granular bed was observed through direct visualization. As the intruder particle reaches the top surface, the LabVIEW program/stop watch counter will be stopped and the elapsed time will be recorded. At the end of each experimental trial, the dry sand particles will be removed from the Perspex box as well as the intruder particle. The experimental procedure is repeated for the next experimental trial.

\section{RESULTS AND DISCUSSIONS}

In an attempt to observe the "Brazil nut effect" (BNE), a non-cohesive granular material subjected to vertical vibration in a container (Perspex box) containing dry sand of particles size ranging from $26 \mu \mathrm{m}-2000 \mu \mathrm{m}$ was used in this study. The large single particle (intruder) of different sizes $\&$ densities and made from different materials (i.e glass, nylon and steel) were used as the intruder particles in this study. Series of tests were conducted for different intruder particles, at different granular bed heights and frequencies of vibration at constant acceleration of $4 \mathrm{~g}$ and $5 \mathrm{~g}$ and then at fixed frequency and variable acceleration in the 
range $3 \mathrm{~g}-7 \mathrm{~g}$. All the experimental trials in the study were carried out in a laboratory and the influence of relative humidity on the rise time of the intruder are negligible.

In a series of observations (i.e seven observations in this study), the rise time of the intruder have been reported by computing the best estimate in the observations, standard uncertainty, 95\% confidence limits in the estimate and finally, the result was quoted in terms of the best estimate and the expanded uncertainty in the observations.

It was found that the experimental results obtained using the oscilloscope based experimental set up were far better than those obtained with the LabVIEW based experimental set up under identical vibratory conditions. The LabVIEW based experimental results are attached in the appendix. The group of experimental results plotted in Figure 2 - 13 are for fixed acceleration of $4 \mathrm{~g}$ and $5 \mathrm{~g}$ in the frequency range between $20 \mathrm{~Hz}-100 \mathrm{~Hz}$ and those plotted in Figure $14-.22$ are for fixed frequency of $40 \mathrm{~Hz}, 60 \mathrm{~Hz}$ and $80 \mathrm{~Hz}$ with acceleration range between $3 \mathrm{~g}-4 \mathrm{~g}$. The analysis in this study is based on the following types of information:

$>$ Assessment of the segregation rate of the intruder (i.e how long will it take the intruder to rise to the top) under the different vibratory conditions.

$>$ Determination of the effects of the different granular bed depth on the intruder's segregation rate.

$>$ Determination of the effects of the particle (intruder) size and density difference on the segregation rate.

\subsection{Influence of frequency at constant acceleration}

[13] suggested that frequency of vibration seems to be an important parameter affecting the segregation mechanism for fixed vibration acceleration. Figure 2 to Figure 13 shows a detailed analysis for the various intruder particles. From the results, the effects of varying the frequency of vibration was observed even though the frequency range $(20 \mathrm{~Hz}-65 \mathrm{~Hz})$ considered in this study was small

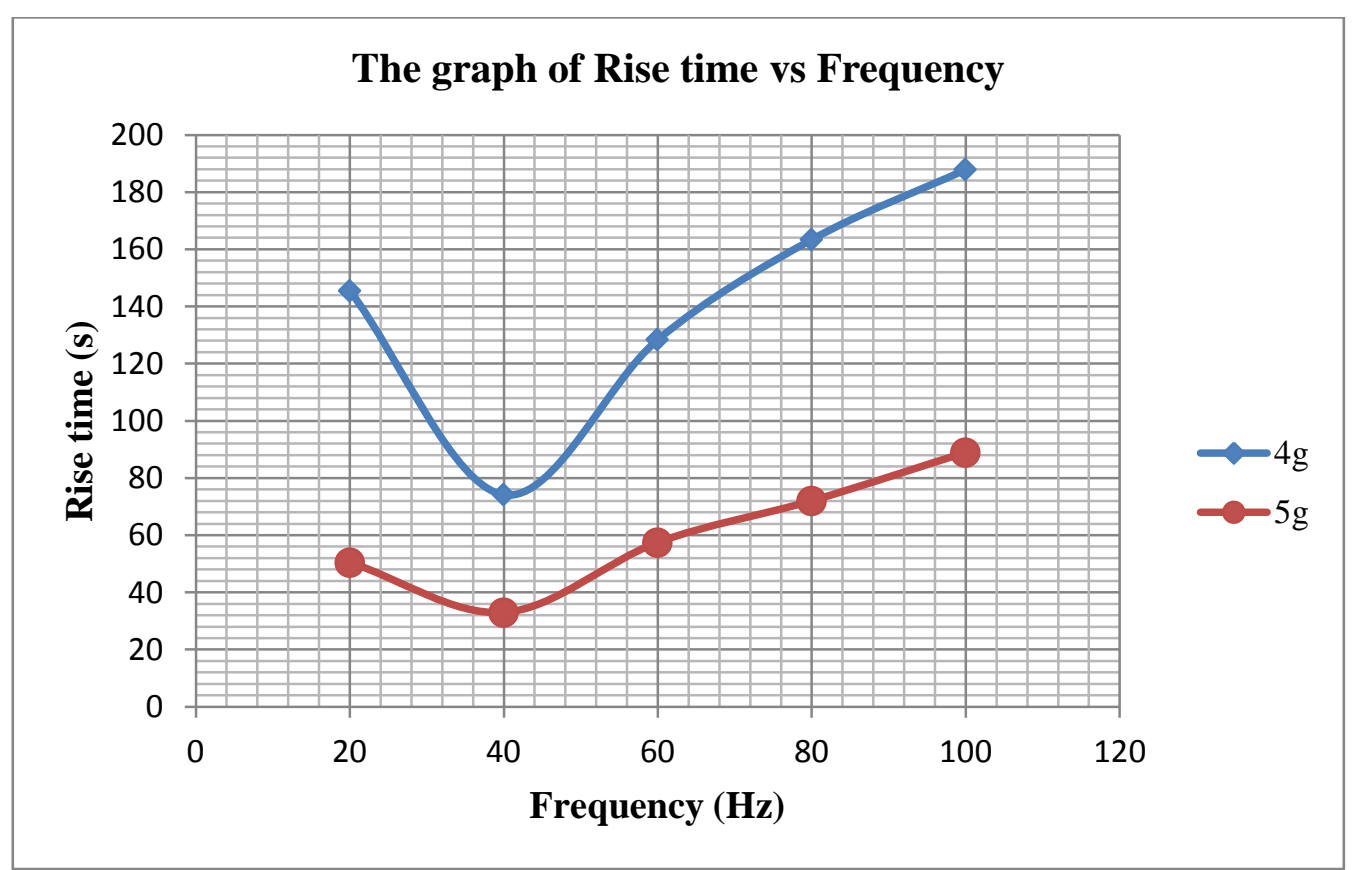

Figure 2 Effect of frequency of vibration on segregation

Depth of bed $=75 \mathrm{~mm}$. position of large particle: silica glass of size $6 \mathrm{~mm}$ placed at bottom centre position. Vibration conditions: fixed acceleration of $4 \mathrm{~g}$ and $5 \mathrm{~g}$ but variable frequency. 
International Journal of Advances in Scientific Research and Engineering (ijasre), Vol 5 (12), December-2019

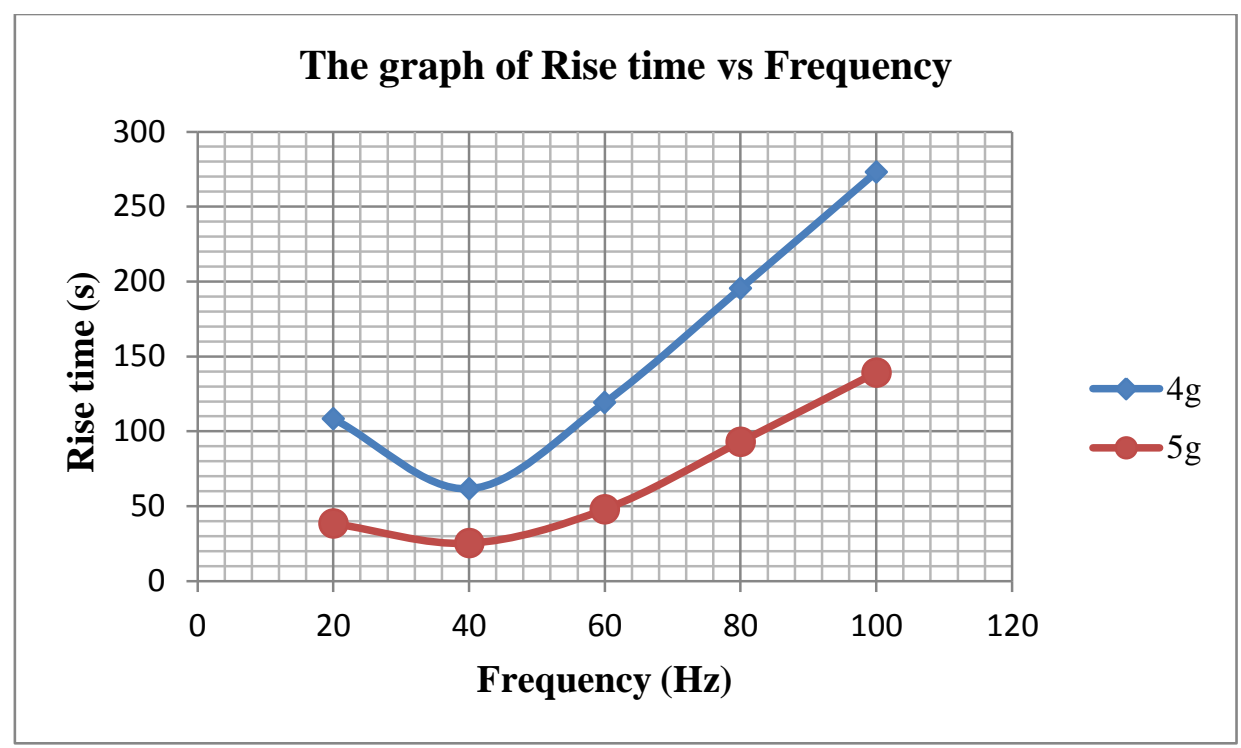

Figure 3 Effect of frequency of vibration on segregation

Depth of bed $=100 \mathrm{~mm}$. position of large particle: silica glass of size $6 \mathrm{~mm}$ placed at bottom centre position. Vibration conditions: fixed acceleration of $4 \mathrm{~g}$ and $5 \mathrm{~g}$ but variable frequency.

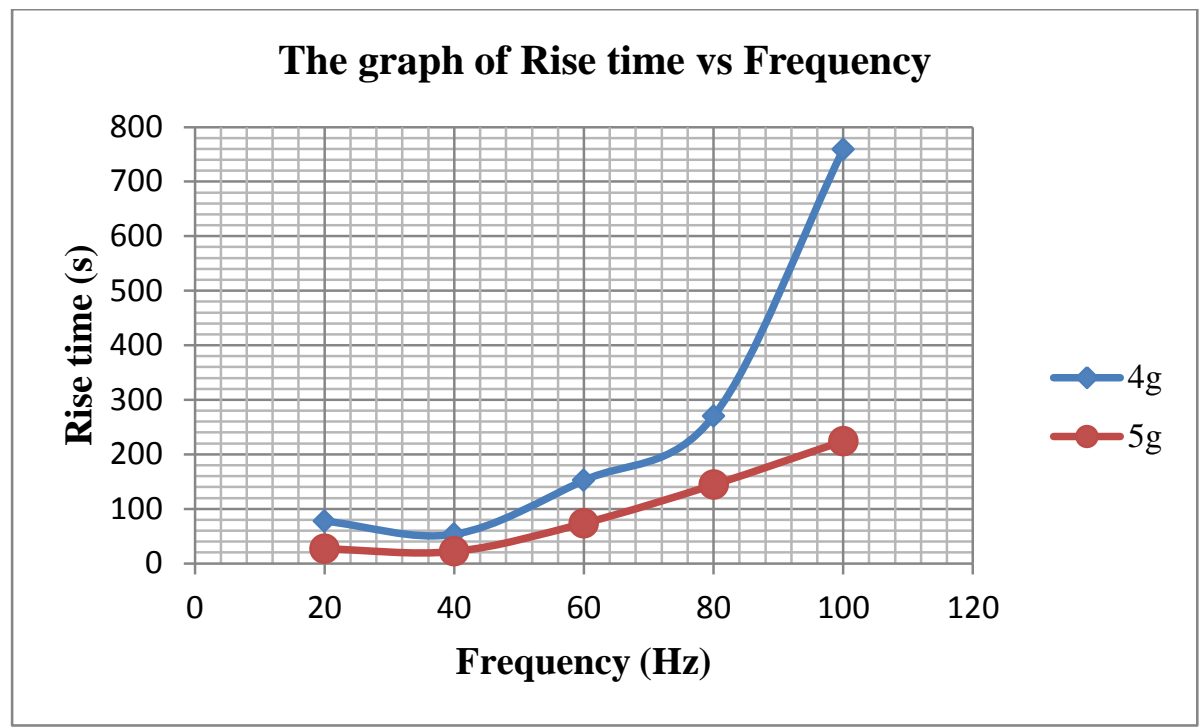

Figure 4 Effect of frequency of vibration on segregation

Depth of bed $=125 \mathrm{~mm}$. position of large particle: silica glass of size $6 \mathrm{~mm}$ placed at bottom centre position. Vibration conditions: fixed acceleration of $4 \mathrm{~g}$ and $5 \mathrm{~g}$ but variable frequency

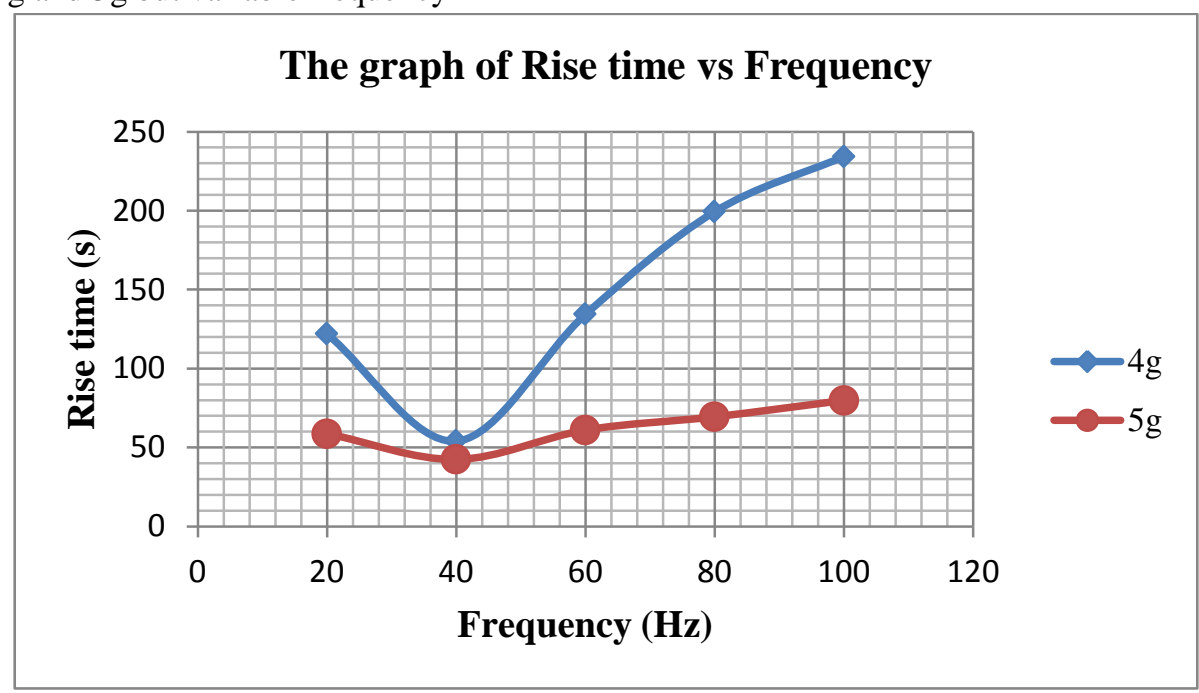

Figure 5 Effect of frequency of vibration on segregation

Depth of bed $=75 \mathrm{~mm}$. position of large particle: nylon of size $6 \mathrm{~mm}$ placed at bottom centre position. Vibration conditions: fixed acceleration of $4 \mathrm{~g}$ and $5 \mathrm{~g}$ but variable frequency 
International Journal of Advances in Scientific Research and Engineering (ijasre), Vol 5 (12), December-2019

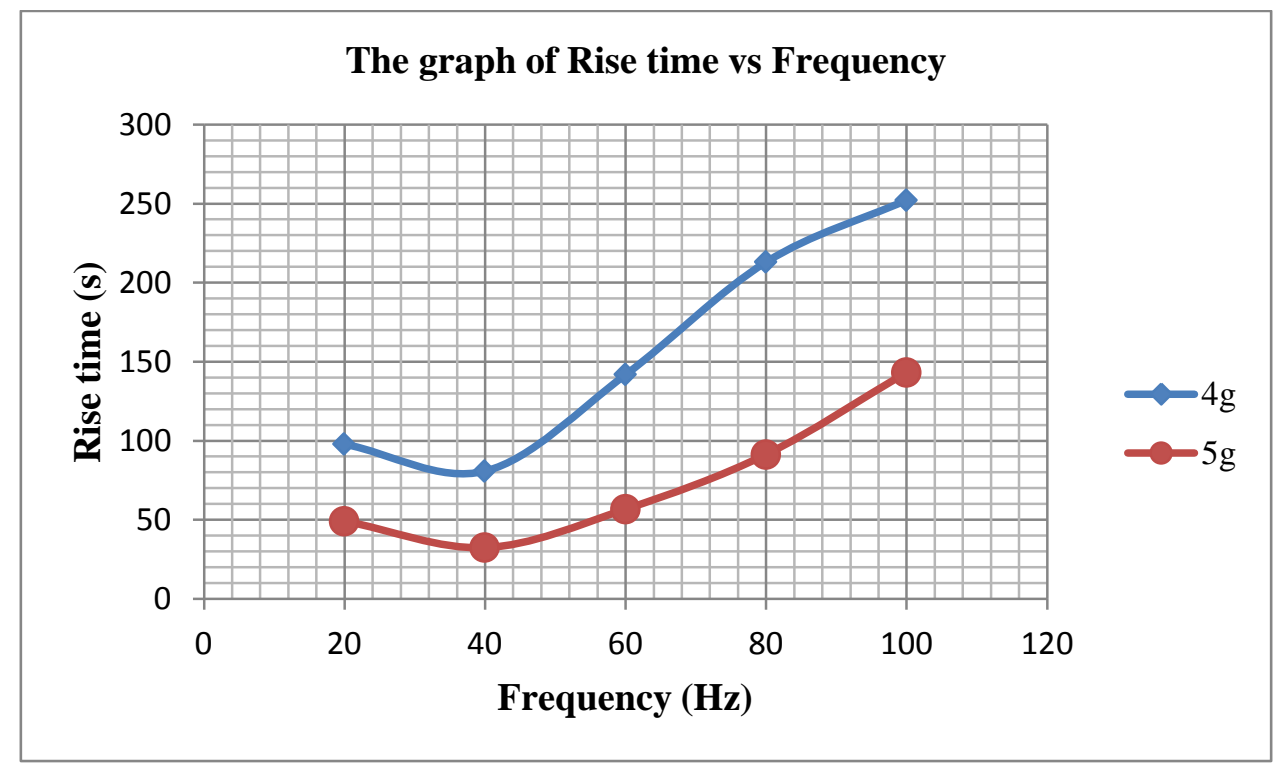

Figure 6 Effect of frequency of vibration on segregation

Depth of bed $=100 \mathrm{~mm}$. position of large particle: Nylon of size $6 \mathrm{~mm}$ placed at bottom centre position. Vibration conditions: fixed acceleration of $4 \mathrm{~g}$ and $5 \mathrm{~g}$ but variable frequency

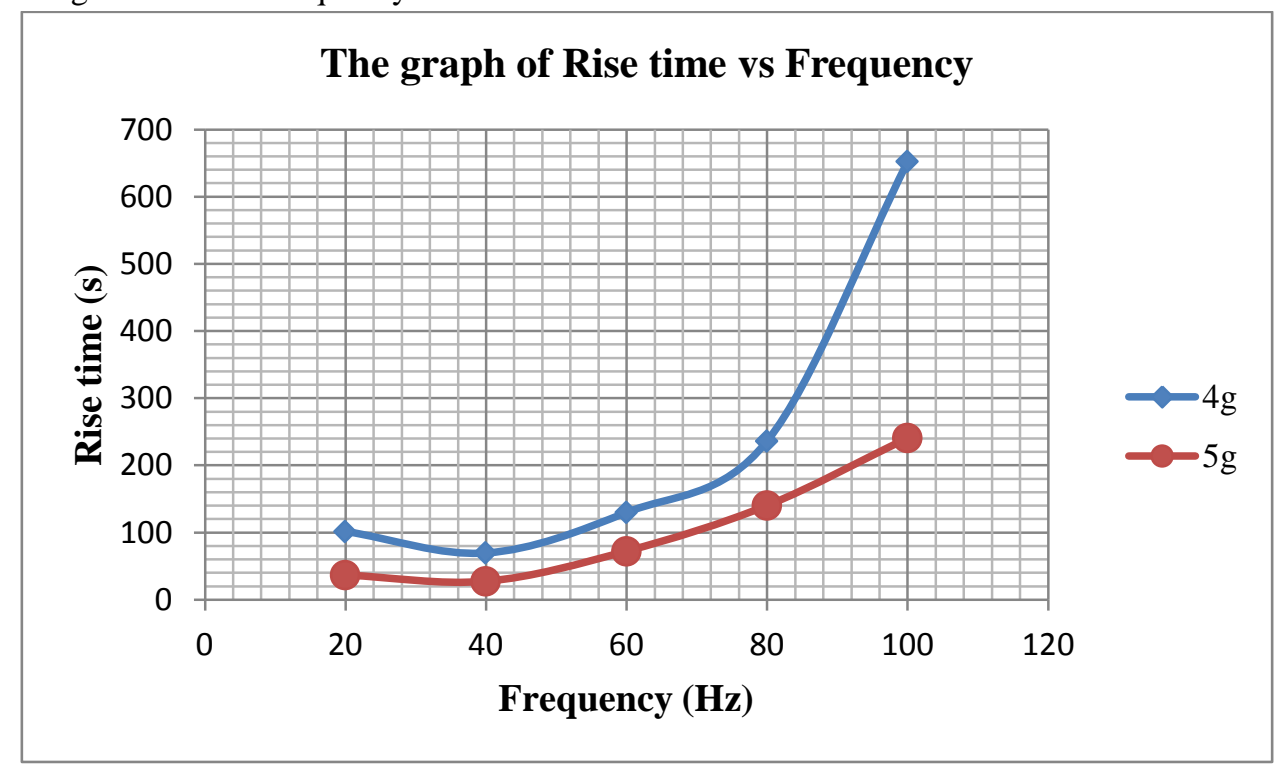

Figure 7 Effect of frequency of vibration on segregation

Depth of bed $=125 \mathrm{~mm}$. position of large particle: Nylon of size $6 \mathrm{~mm}$ placed at bottom centre position. Vibration conditions: fixed acceleration of $4 \mathrm{~g}$ and $5 \mathrm{~g}$ but variable frequency. 
International Journal of Advances in Scientific Research and Engineering (ijasre), Vol 5 (12), December-2019

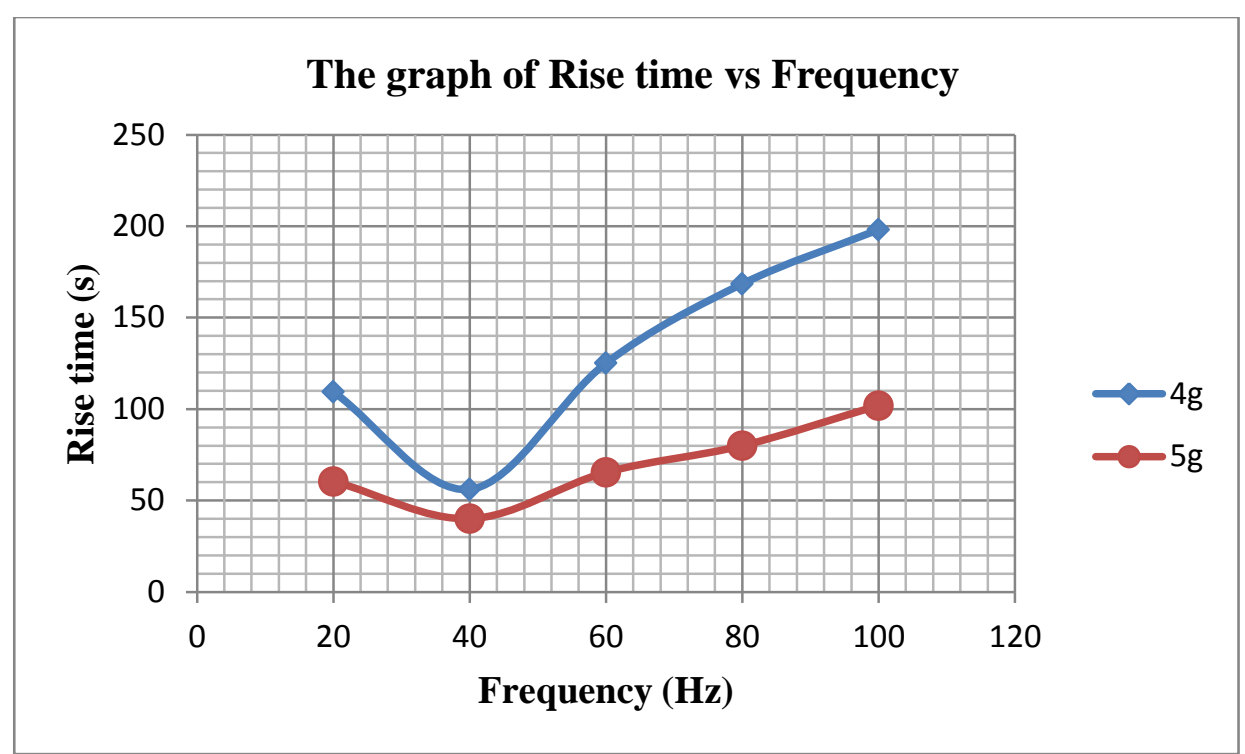

Figure 8 Effect of frequency of vibration on segregation

Depth of bed $=75 \mathrm{~mm}$. position of large particle: silica glass of size $3 \mathrm{~mm}$ placed at bottom centre position. Vibration conditions: fixed acceleration of $4 \mathrm{~g}$ and $5 \mathrm{~g}$ but variable frequency.

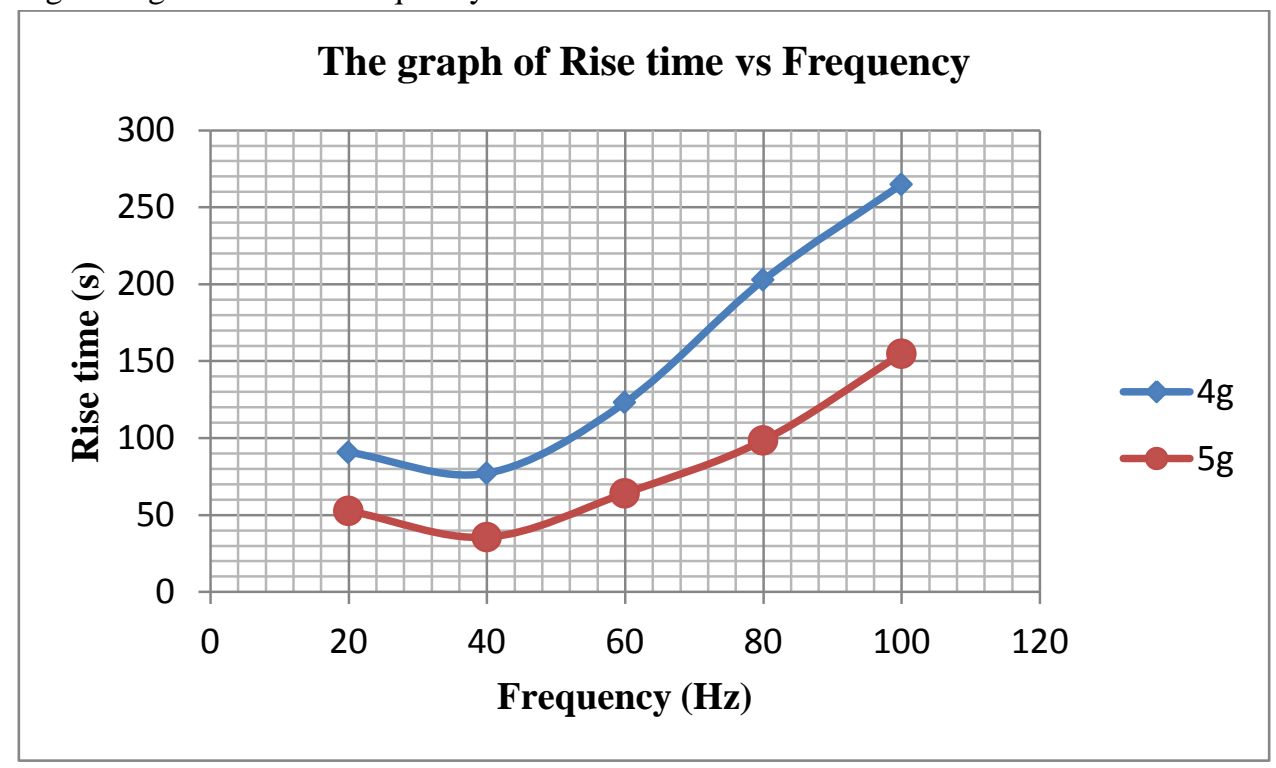

Figure 9 Effect of frequency of vibration on segregation

Depth of bed $=100 \mathrm{~mm}$. position of large particle: silica glass of size $3 \mathrm{~mm}$ placed at bottom centre position. Vibration conditions: fixed acceleration of $4 \mathrm{~g}$ and $5 \mathrm{~g}$ but variable frequency.

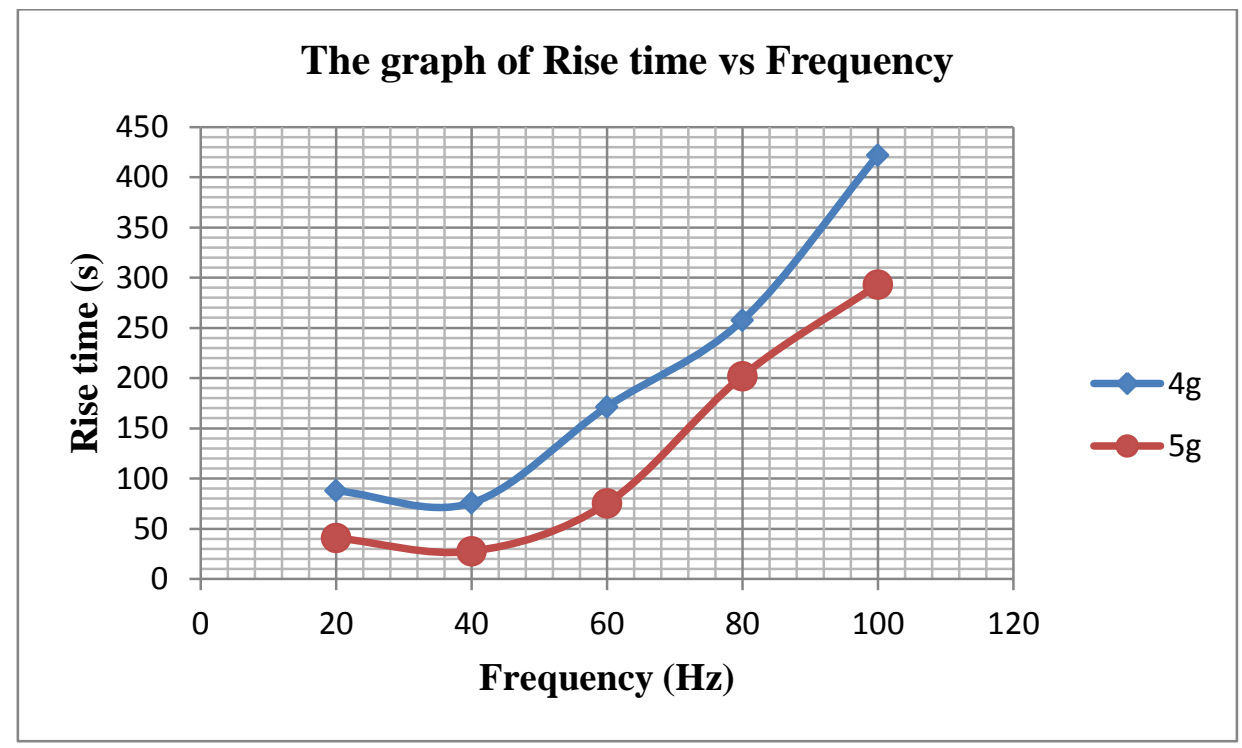

Figure 10 Effect of frequency of vibration on segregation 
International Journal of Advances in Scientific Research and Engineering (ijasre), Vol 5 (12), December-2019

Depth of bed $=125 \mathrm{~mm}$. position of large particle: silica glass of size $3 \mathrm{~mm}$ placed at bottom centre position. Vibration conditions: fixed acceleration of $4 \mathrm{~g}$ and $5 \mathrm{~g}$ but variable frequency.

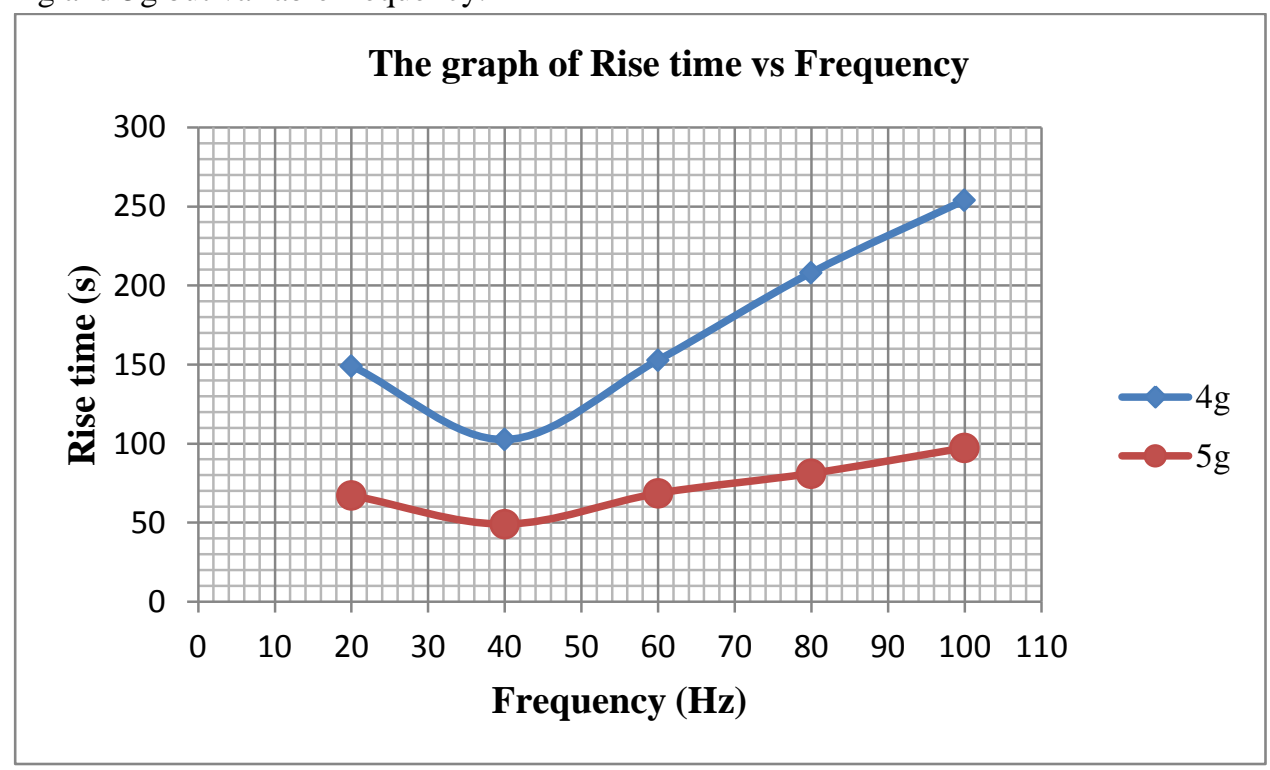

Figure 11 Effect of frequency of vibration on segregation

Depth of bed $=75 \mathrm{~mm}$. position of large particle: nylon of size $3.18 \mathrm{~mm}$ placed at bottom centre position. Vibration conditions: fixed acceleration of $4 \mathrm{~g}$ and $5 \mathrm{~g}$ but variable frequency.

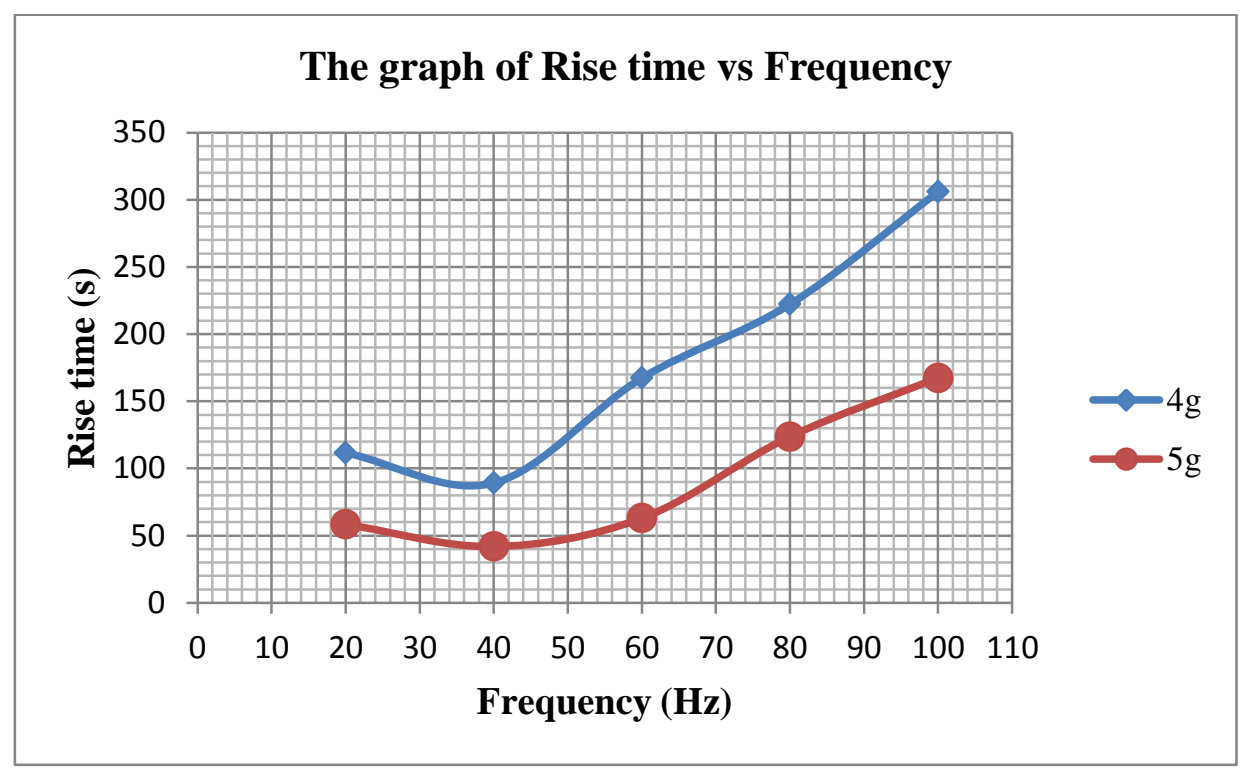

Figure 12 Effect of frequency of vibration on segregation

Depth of bed $=100 \mathrm{~mm}$. position of large particle: nylon of size $3.18 \mathrm{~mm}$ placed at bottom centre position. Vibration conditions: fixed acceleration of $4 \mathrm{~g}$ and $5 \mathrm{~g}$ but variable frequency. 


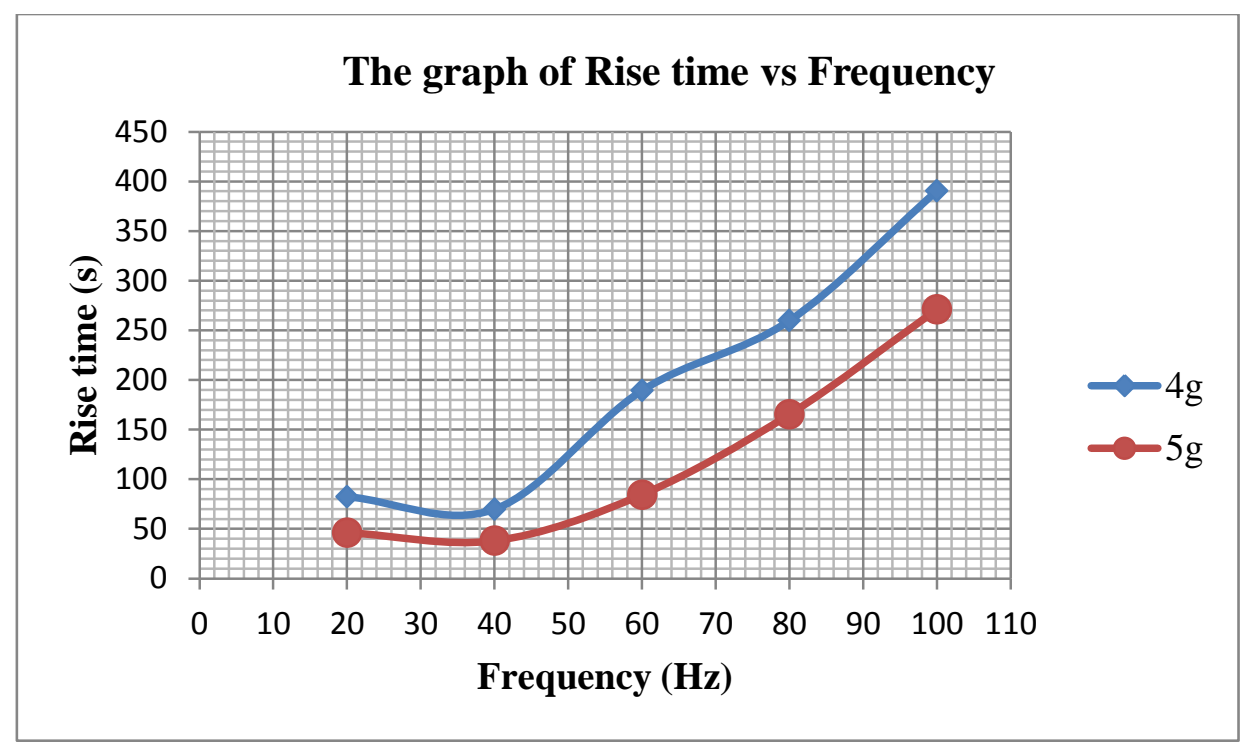

Figure 13 Effect of frequency of vibration on segregation

Depth of bed $=125 \mathrm{~mm}$. position of large particle: nylon of size $3.18 \mathrm{~mm}$ placed at bottom centre position. Vibration conditions: fixed acceleration of $4 \mathrm{~g}$ and $5 \mathrm{~g}$ but variable frequency.

Interestingly, these Figures have revealed trends of behaviour worthy of note. The rise time of the intruder particle for different experiments is plotted against the frequency in these figures. Loosely speaking, it was observed that, at frequency range $20 \mathrm{~Hz}-$ $40 \mathrm{~Hz}$, the segregation rate decreases which implies segregation is increased with increasing frequency. However, this behaviour is counter-intuitive for frequencies higher than the frequency in the range as the segregation rate seems to increase with frequency. Mass movement of the granular bed shows that the changing behaviour may be attributed to the change in flow regime. Conversely, at frequencies less than $40 \mathrm{~Hz}$, the flow regime is observed to be of the heap and convention type. In addition at frequencies above $40 \mathrm{~Hz}$ the flow regime signifies surface fluidisation with virtual random motion and no heaping occurs. Evidently, however, it is clear that the bulk density of the granular bed increases and the intruder takes longer time before reaching the top surface at high frequency. In general sense, increasing the acceleration level to $5 \mathrm{~g}$ tends to increase the segregation rate. It could therefore be concluded that the acceleration parameter is a major parameter controlling segregation.

In addition, as the large intruder particle reaches the top surface, it stays there because the convection currents are too narrow to sweep it down along the wall.

\subsection{Effect of depth of granular depth}

The effect of depth of granular bed on the segregation phenomenon was investigated in this study. In this case measurements of the intruder rise time were plotted as a function of the acceleration for various depth of granular bed at constant frequency of 40 $\mathrm{Hz}, 60 \mathrm{~Hz}$ and $80 \mathrm{~Hz}$ for nylon intruder particle of size $6 \mathrm{~mm}$ and this is as shown in Figure 14 to Figure 16.

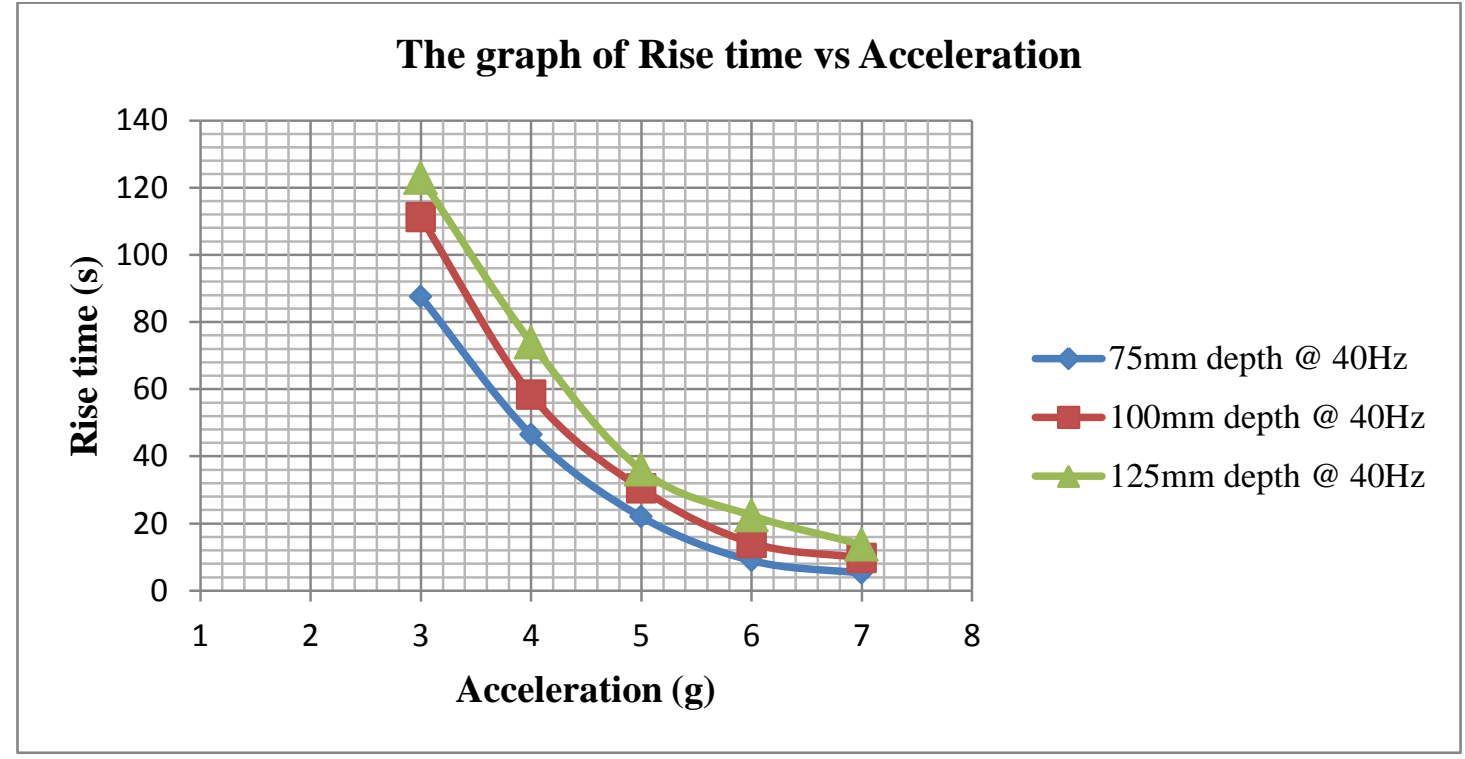

Figure 14 Effect of granular bed depth on segregation. 
Depth of bed $=75 \mathrm{~mm}, 100 \mathrm{~mm}, 125 \mathrm{~mm}$. Position of large particle: nylon of size $6 \mathrm{~mm}$ placed at bottom centre position. Vibration conditions: variable acceleration and constant frequency of $40 \mathrm{~Hz}$.

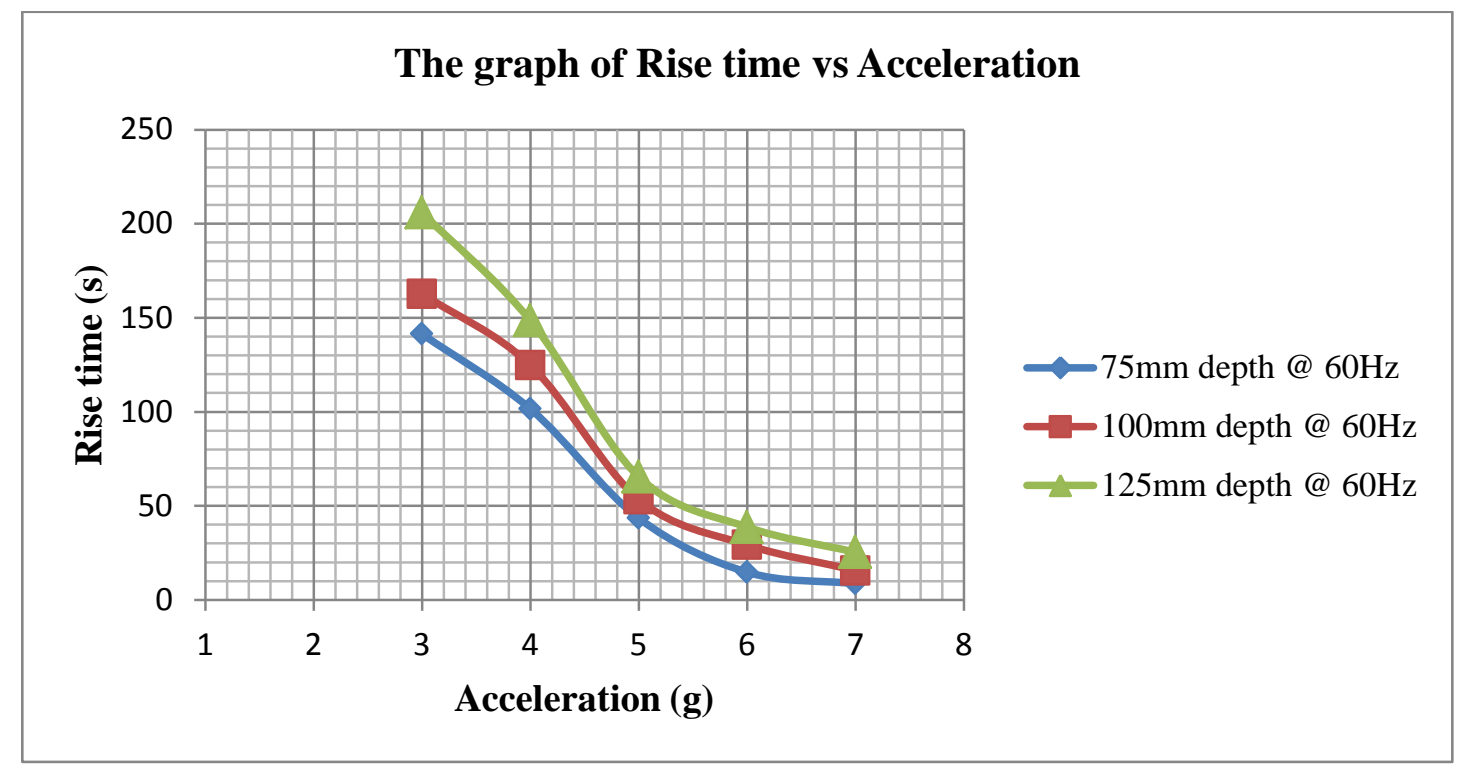

Figure 15 Effect of granular bed depth on segregation.

Depth of bed $=75 \mathrm{~mm}, 100 \mathrm{~mm}, 125 \mathrm{~mm}$. Position of large particle: nylon of size $6 \mathrm{~mm}$ placed at bottom centre position. Vibration conditions: variable acceleration and constant frequency of $60 \mathrm{~Hz}$.

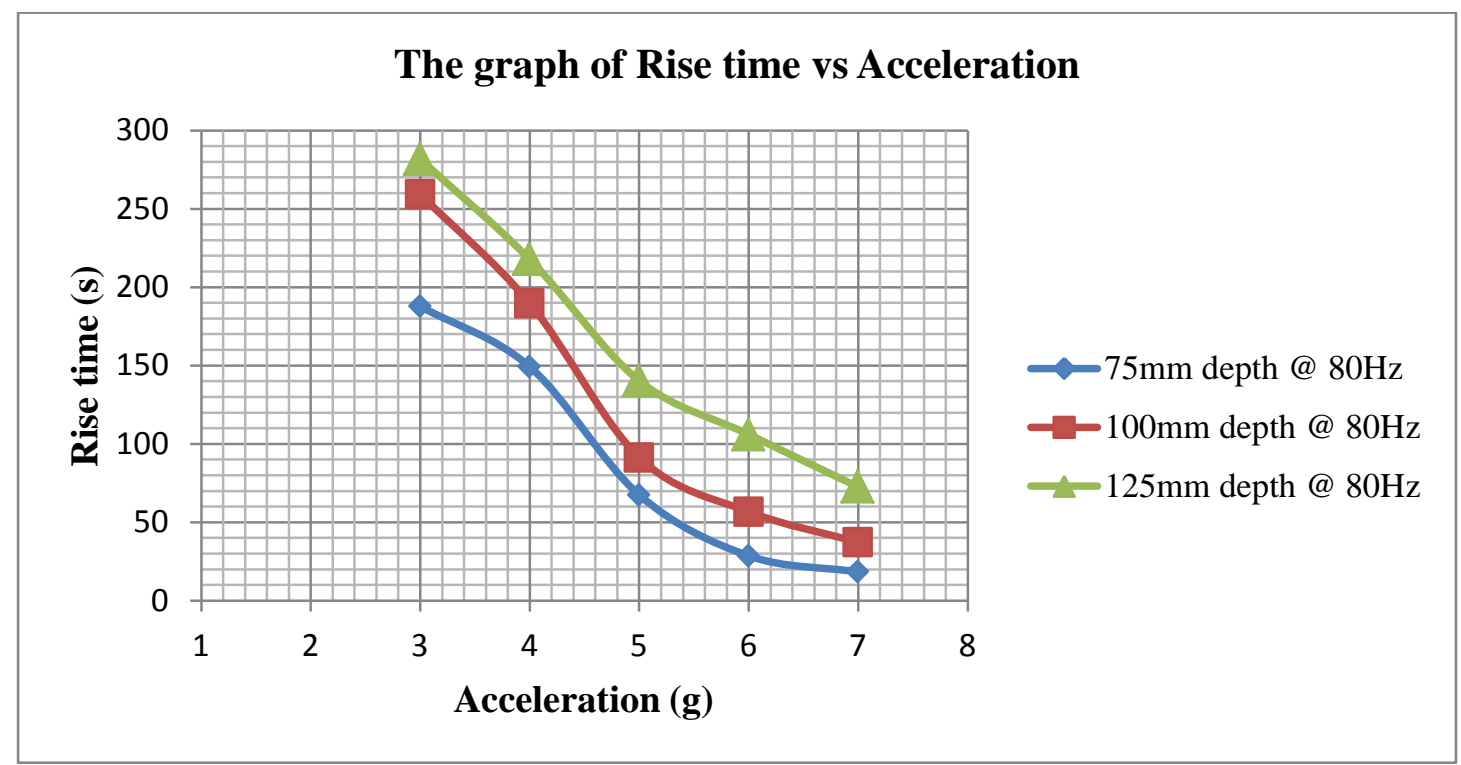

Figure 16 Effect of granular bed depth on segregation.

Depth of bed $=75 \mathrm{~mm}, 100 \mathrm{~mm}, 125 \mathrm{~mm}$. Position of large particle: nylon of size $6 \mathrm{~mm}$ placed at bottom centre position. Vibration conditions: variable acceleration and constant frequency of $80 \mathrm{~Hz}$.

The findings of Figure 14, Figure 15, and Figure 16 are interesting in that they make it clear that the rise time of the intruder increases with granular bed depth at constants frequency. However, it is important to note that there exist no direct significance between the granular bed depth and the rise time under similar vibratory conditions.

\subsection{Influence of size of large intruder particle}

The influence of the size of the intruder particle on the segregation speed of the particle has been investigated experimentally using particles having approximately the same density $\left(\approx 2.50 \mathrm{~g} / \mathrm{cm}^{3}\right)$ but different sizes $(3 \mathrm{~mm}$ and $6 \mathrm{~mm})$ and made from the same materials (silica glass) . The results obtained were plotted as shown in Figure 17.0 to Figure 19.0. 
International Journal of Advances in Scientific Research and Engineering (ijasre), Vol 5 (12), December-2019

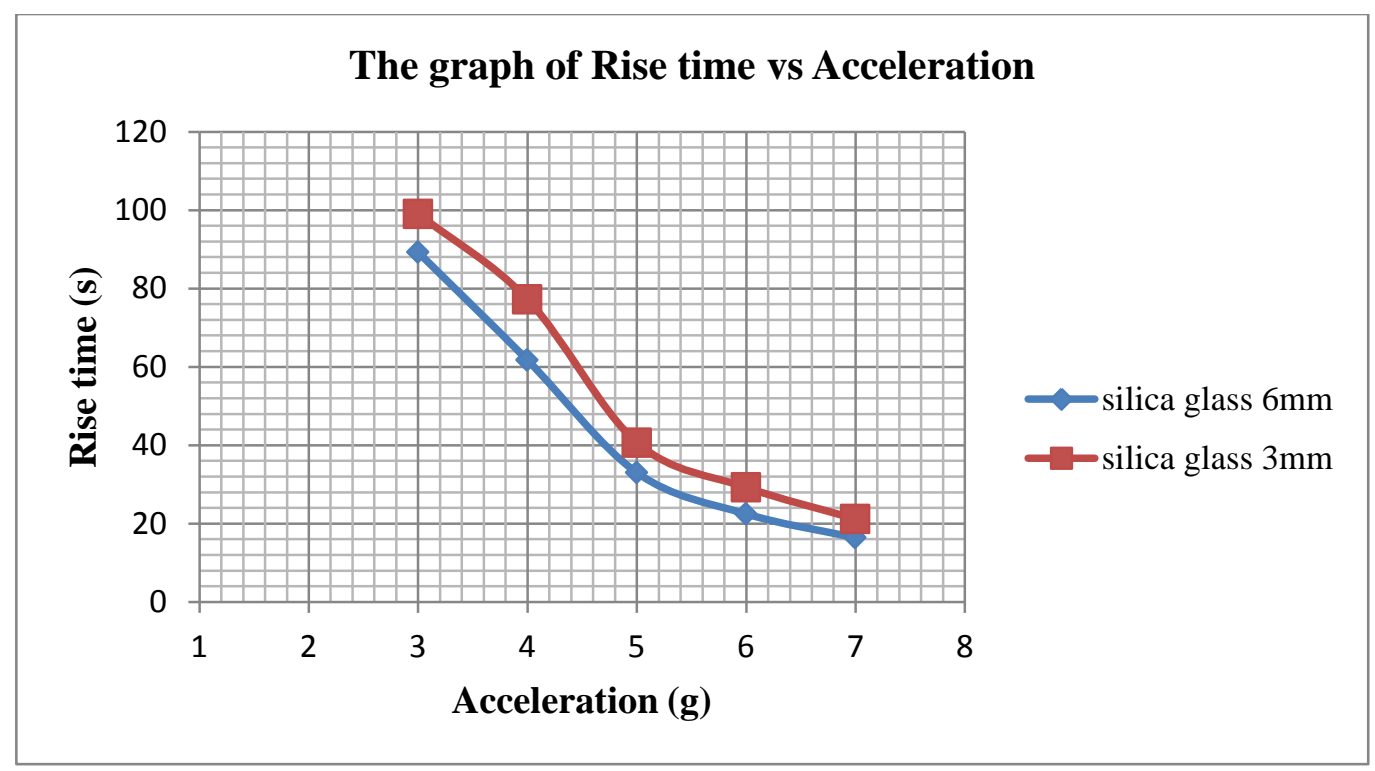

Figure 17 Effect of intruder particle size on segregation.

Depth of bed $=100 \mathrm{~mm}$. Position of large particle: silica glass of size $6 \mathrm{~mm}$ and $3 \mathrm{~mm}$ placed at bottom centre position. Vibration conditions: variable acceleration and constant frequency of $40 \mathrm{~Hz}$.

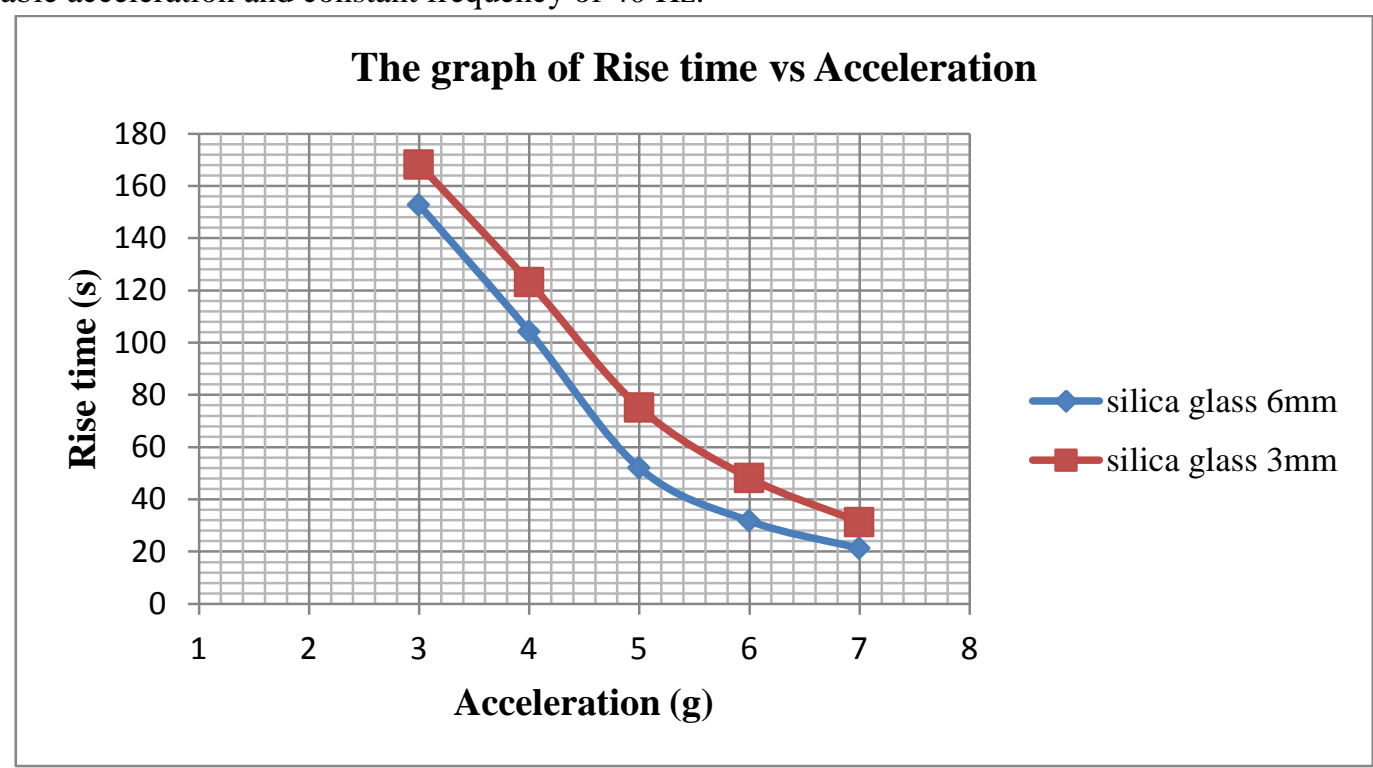

Figure 18 Effect of intruder particle size on segregation.

Depth of bed $=100 \mathrm{~mm}$. Position of large particle: silica glass of size $6 \mathrm{~mm}$ and $3 \mathrm{~mm}$ placed at bottom centre position. Vibration conditions: variable acceleration and constant frequency of $60 \mathrm{~Hz}$.

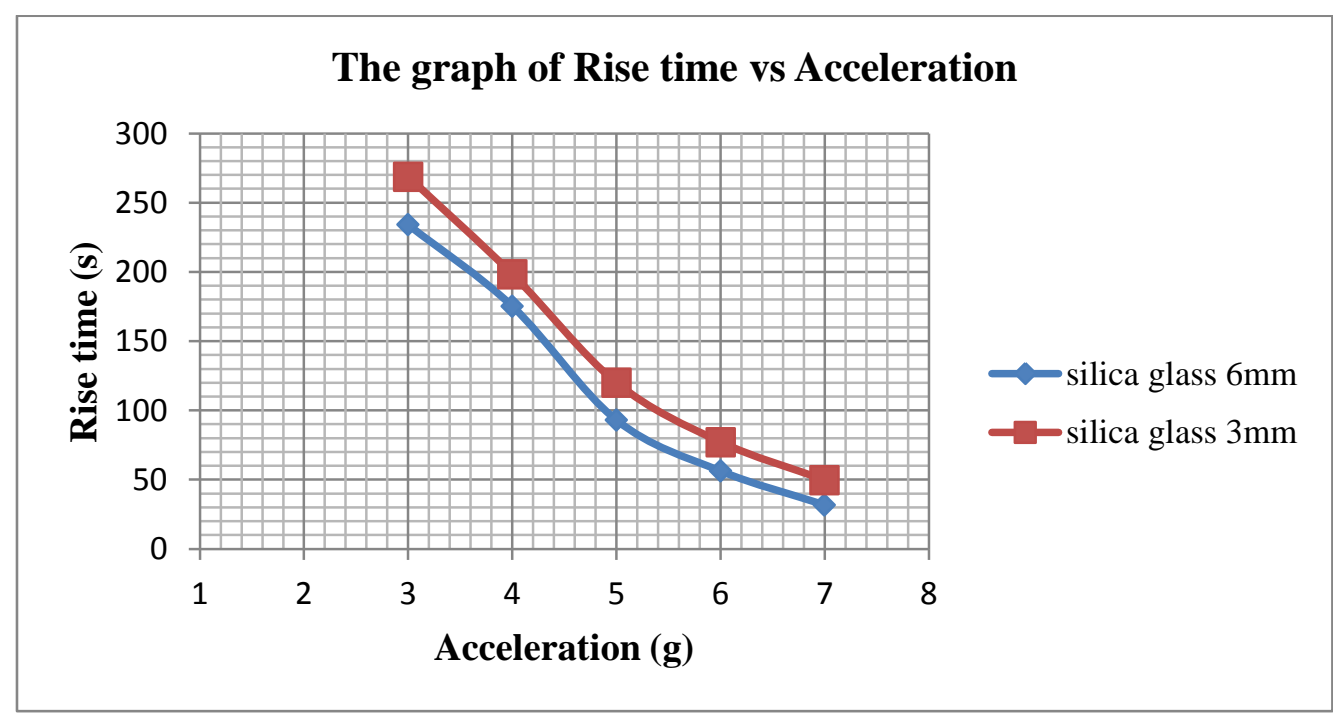

Figure 19 Effect of intruder particle size on segregation. 
Depth of bed $=100 \mathrm{~mm}$. Position of large particle: silica glass of size $6 \mathrm{~mm}$ and $3 \mathrm{~mm}$ placed at bottom centre position. Vibration conditions: variable acceleration and constant frequency of $80 \mathrm{~Hz}$.

From Figure 17, Figure 18 and Figure 19, it could be deduced that the larger the size of the intruder particle the faster it rises to the top surface. However, as the vibration intensity (acceleration) increases, it was found that the rise time further decreases thereby increasing the segregation of the large particle.

\subsection{Effect of density of large intruder particle}

Steel ball, silica glass bead and nylon bead of size $6 \mathrm{~mm}$ having densities of $7.81 \mathrm{~g} / \mathrm{cm}^{3}, 2.50 \mathrm{~g} / \mathrm{cm}^{3}$ and $1.15 \mathrm{~g} / \mathrm{cm}^{3}$ were used to investigate the effect of the intruder density on its segregation at constant granular bed depth of $75 \mathrm{~mm}$ under different vibratory conditions. The results obtained from the study were shown in Figure 20, 21 and 22.

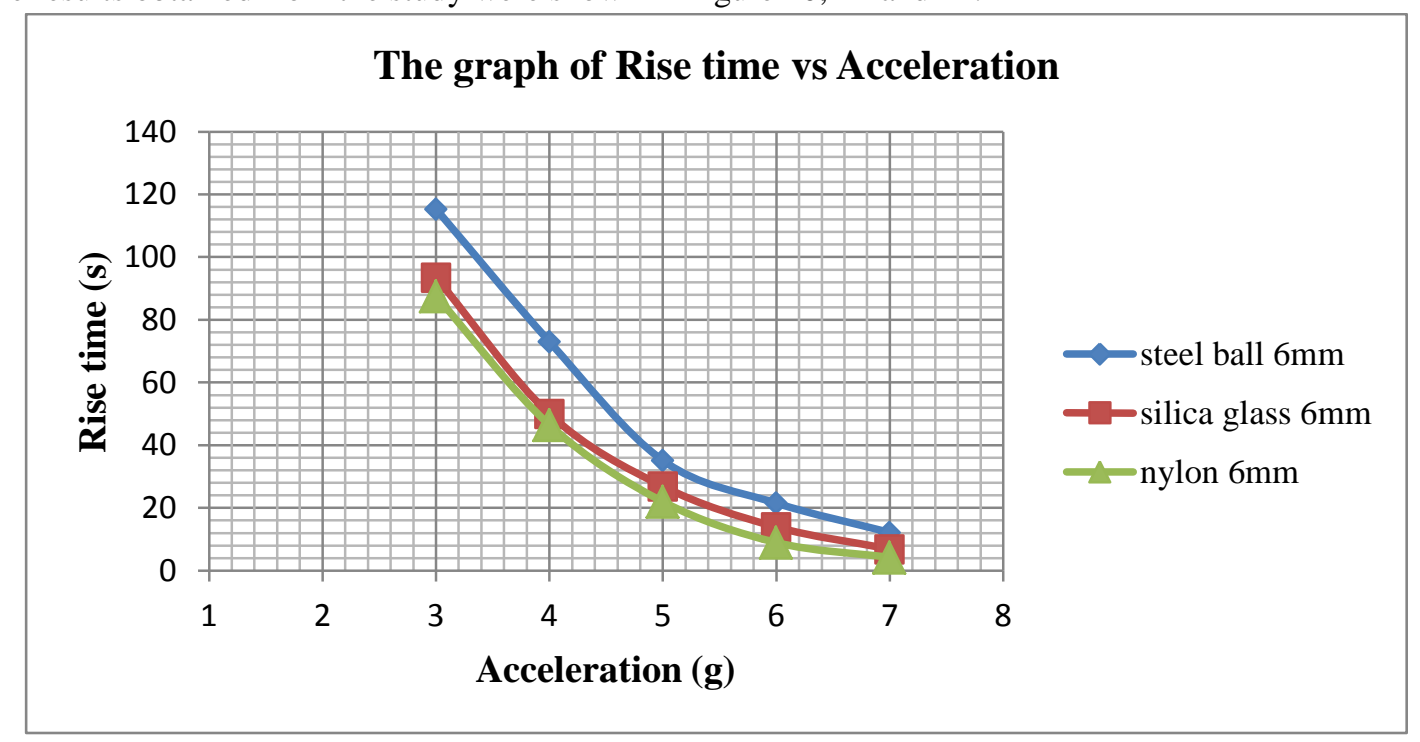

Figure 20 Effect of intruder density on segregation.

Depth of bed $=75 \mathrm{~mm}$. Position of large particles: steel ball, silica glass and nylon of size 6mm placed at bottom centre position. Vibration conditions: variable acceleration and constant frequency of $40 \mathrm{~Hz}$.

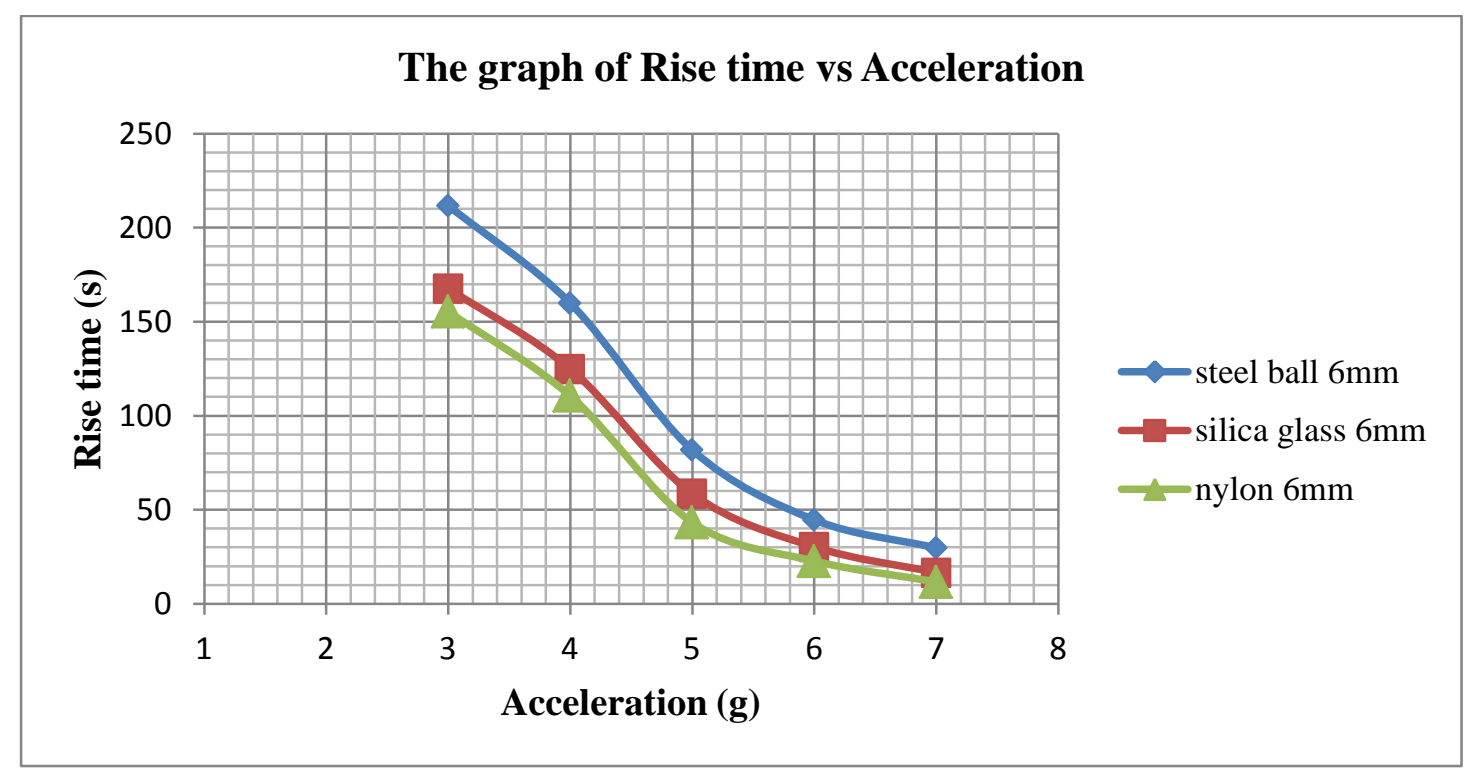

Figure 21 Effect of intruder density on segregation.

Depth of bed $=75 \mathrm{~mm}$. Position of large particles: steel ball, silica glass and nylon of size 6mm placed at bottom centre position. Vibration conditions: variable acceleration and constant frequency of $60 \mathrm{~Hz}$. 


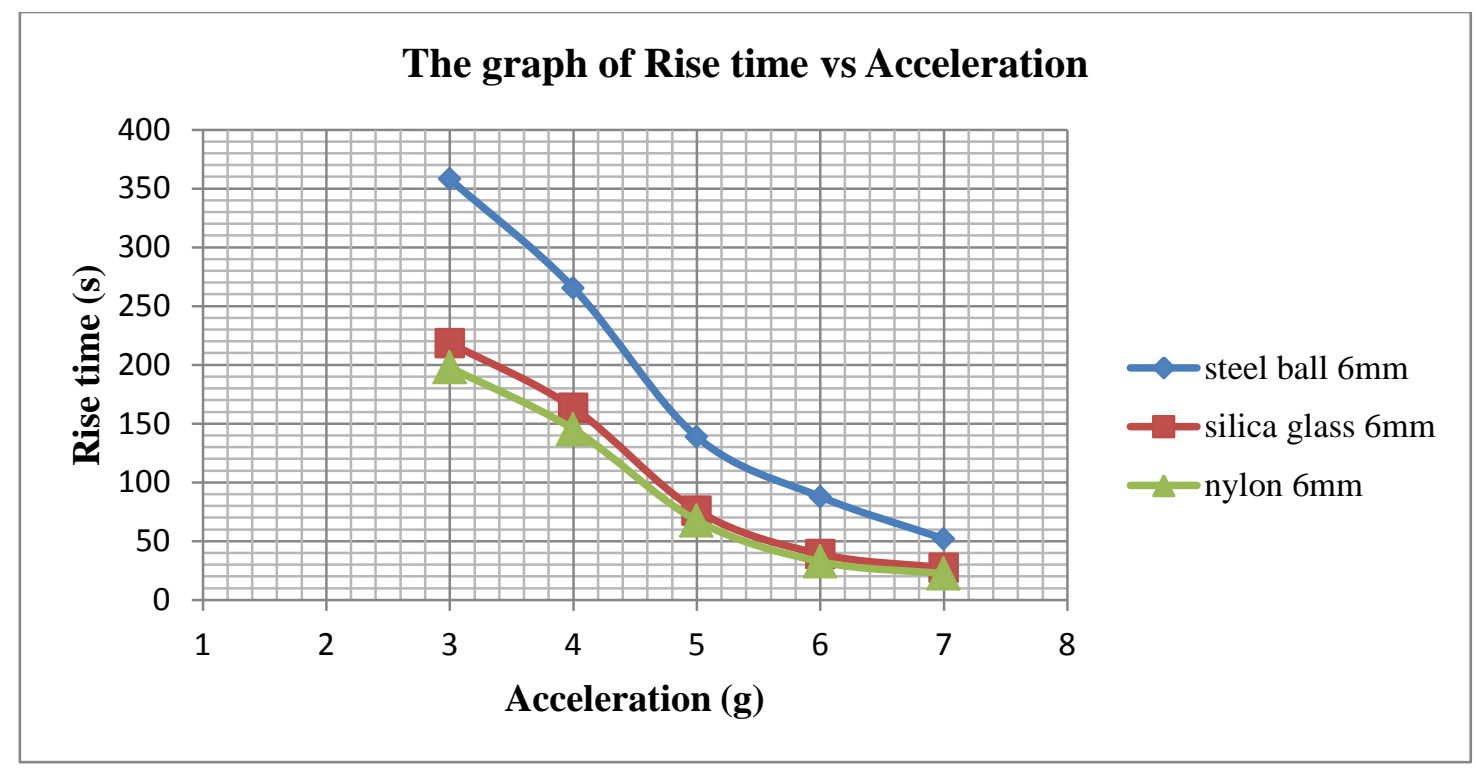

Figure 22 Effect of intruder density on segregation

Depth of bed $=75 \mathrm{~mm}$. Position of large particles: steel ball, silica glass and nylon of size $6 \mathrm{~mm}$ placed at bottom centre position. Vibration conditions: variable acceleration and constant frequency of $80 \mathrm{~Hz}$.

Figure 20, Figure 21 and Figure 22, showed that as the density of the intruder large particle increases, the rise time increases (i.e segregation decreases). In another sense the heavier the intruder particle the lower is the tendency to segregate. Moreover, from close observation of these figures it can be said with great confidence that the rise time of the intruder particle is simply the reciprocal of the acceleration $\left(a_{c c} \alpha \frac{1}{\sqrt{\mathrm{trd}_{\mathrm{rd}}}}\right)$. Furthermore, at frequency of $40 \mathrm{~Hz}$ and $80 \mathrm{~Hz}$, the influence of density could be negligible for silica glass bead and nylon bead of equal sizes.

\section{RESULT AND DISCUSSION}

Preliminary results from a series of experimental trials on the rise of a single large intruder particle in a vibrated granular bed consisting of grains for dry sand are presented in this paper. These results represent a part of the ongoing experimental investigation of the mechanism of size segregation in vibrated granular beds. Put simply, when granular beds are vibrated vertically, the large particles were observed to rise to the top surface, even though the underlying mechanisms behind it have been the subject of argument among a number of significant researchers. For the purpose of illustration, [3] in their seminal work have argued that the intruder particle move upward as a result of void filling mechanism which causes the grains to fall into the voids produced under the large particles. Moreover, [11-12] proposed that in vibrated granular bed consisting of grains of dry sand, airdriven effects contribute largely to the migration of the large particle to the upward surface.

Interestingly, most of the findings from the current study have corroborated some of the work previously reported by other several researchers. However, the significant revelation from this study is that frequency may be an important parameter influencing the phenomenon of segregation, as indicated by the plots of the rise time versus frequency. It was further observed that with increasing frequency and constant acceleration, the segregation rate decreases within a certain range of frequency. Furthermore, as the acceleration increases, the segregation further increases. This finding presented here, qualitatively is similar to the experimental results of [14]. It was, however, more evident from Figure 2 through Figure 13 that within a frequency range of 20 $\mathrm{Hz}-40 \mathrm{~Hz}$ the segregation increases with frequency and beyond $40 \mathrm{~Hz}$ segregation decreases with increase in frequency. Probable reason this important observation is due to the different flow regimes existing between the considered frequency ranges. This is also the finding of [15] in their seminal work involving 3-D experimental tests with $3 \mathrm{~mm}$ acrylic spheres in a cylindrical container that was vibrated by sinusoidal variations of a floor piston at vibration frequency $f$ and displacement amplitude $a_{o}$. In the study three flow regimes characterised by vibration parameters were observed. First, at frequency of roughly $\mathrm{f} \approx 15 \mathrm{~Hz}$, surface heaping and strong convective flow were observed. In this regime $\mathrm{T} f$ scales exponentially with $f$. Second at frequency regime defined by $15 \mathrm{~Hz}<f<40 \mathrm{~Hz}$, surface heaping seize to exist but still convection flow tend to provide the driving mechanism for the segregation. Lastly, at frequency regime of between $40 \mathrm{~Hz}$ and $75 \mathrm{~Hz}$, the vibration amplitude becomes much smaller than the size of the granular bed grains, an increase in bulk density of the granular bed will be experienced and the intruder particle therefore takes longer time to reach to the top surface. This flow regime is generally characterised as the non-convective flow regime. Theoretically, however, acceleration is defined by $\mathrm{A} w^{2}(w=2 \pi f)$. This implies that at constant acceleration as the 
frequency increases, the amplitude becomes relatively small. Consequently, the granular bed will become more compacted and the intruder particle migrates to the top surface slowly.

More importantly, the findings of Figures 14 - 16 are worthy of note. The rise time of the large intruder particle was observed to increase with granular bed depth at constant frequency. In another sense, segregation is decreased with increase in granular bed depth. This is probably due to the fact that with increasing granular bed depth the upward flow in the centre seemed to decrease. This assertion has been corroborated through the findings of [16]. In their experiment setup, magnetic resonance imaging (MRI) technique in a cylindrical container filled with poppy seeds that were subjected to vertical vibrations at low frequency. The findings show that the resultant movement decreases with increasing depth from the surface.

In addition, the characteristics of particles that enhance segregation rate have been also studied in this research. Particularly, the density and size were the properties considered in the study. From the current study it was observed that the larger the size of the large intruder particle, the greater is the segregation of the particle under identical vibratory conditions. Interestingly, identical qualitative behaviour was observed in the findings of [16]. In their experimental work, steel disks of different sizes were employed. Each of the disks was placed at the bottom of the granular bed and then vibrated at a frequency of $4.45 \mathrm{~Hz}$ and the time it takes the disk reach the surface was recorded. This procedure was repeated five times for each disk and they reported that the total rise time of the disk is inversely proportional to the size of the disk. Broadly speaking, the tendency to segregate is lower for intruder particle with higher density. This assertion was also observed by [17]. This finding was counter-intuitive to the observation of [16]. In their experimental work, [16] and his co-workers studied the movement of disks placed at the base of a vibrated granular bed and the density of the disks of the same size was varied by drilling holes in the disk surfaces. The finding showed that the rise time of the intruder disk is inversely proportional to the density of the intruder disk.

The most significant findings emerging from this study is that the acceleration parameter has been observed to be key parameter in controlling the segregation of the intruder particle under similar vibratory conditions. Figures 2 - 22 have indicated these assertions where an increase in acceleration at constant frequencies further increases the segregation of the intruder particle. In contrary, a decrease in acceleration at the same vibratory condition decreases the segregation of the intruder particle. Intruder particles with roughly equal densities (i.e silica glass and nylon), it was observed that the influence of density on the segregation of the intruder particle was negligible at both lower and higher frequencies.

\section{CONCLUSIONS}

In this study, the segregation of granular materials subjected to vertical vibration was investigated. Experimental test trials involving the movement of large single particle through a dry granular bed of dry sand grains under vertical vibration were conducted. The influences of granular bed depth, frequency, particle density and size on the segregation phenomenon were investigated. Nylon (size: $3.18 \mathrm{~mm}$ and $6 \mathrm{~mm}$ ), steel ball of size $6 \mathrm{~mm}$ and silica glass (size: $3 \mathrm{~mm}$ and $6 \mathrm{~mm}$ ) were the intruder particles used in the study. Based on the experimental results, the following conclusions are made: At constant acceleration, the vibration frequency seems to be the most important parameter influencing the segregation process. Similarly at constant acceleration, the segregation decreases within a certain range as the frequency of vibration increases. The segregation rate (rise time) increases as the bed depth increases under identical vibratory conditions. Segregation increases as the size of the large intruder particle increases. Segregation decreases with large intruder particle of higher density than those with lower density.

\section{REFERENCE}

1. Roskilly, S. J., Colbourn, E. A., Alli, O., Williams, D., Paul, K. A., Welfare, E. H. and Trusty, P. A., (2010). Investigating the effect of shape on particle segregation using Monte Carlao simulation. Powder Technology, Vol. 203 (2), Pp. 211-222.

2. Hogg, R., (2009). Mixing and segregation of powders: Evaluation, Mechanisms and Processes. KONA Powder and Particle Journal, Vol. 27, Pp. 3-17.

3. Rosato, A. D., Blackmore, D. L., Zhang, N. \& Lan, Y., (2002). A perspective on vibration-induced size segregation of granular materials. Chemical Engineering Science, Vol. 57 (2), Pp.265-275.

4. Rosato, A. D., Stranburg,K.J., Prinz, F. B. and Swendsen, R. H., (1987). Why the Brazil nuts are on top: Size Segregation of Particulate Matter By Shaking. Physical review letters, Vol. 58 (10), Pp. 1038-1041.

5. K. T. Aminu, M. M. Jibril, A. J. Gin, "Effects of frequency of vibration on the sigregation of granular materials," Journal of Engineering \& Technology. Faculty of Engineering, Bayero University, Kano,Nigeria, vol. 9(1), 2014.

6. Knight, J. B., Jaeger, H. M, \& Nagel, S. R., (1993). Vibration-induced size separation in granular media: The Convection Connection. Physical Review letters, Vol. 70 (24), Pp. 3728-3721. 
7. Majid, M. \& Walzel, P., (2009). Convection and segregation in vertically vibrated granular beds. Powder Technology, Vol. 192 (3), Pp.311-317.

8. Maobin, H., Xiang-Zhao, K., Qing-Song, W. \& Yong-Hong, W., (2005). Effects of container geometry on granular segregation pattern. Chinese Physics, Vol. 14 (9), Pp. 1844-1849.

9. Elperin, T. \& Golshtein, E., (1997). Effects of convection and friction on size segregation in vibrated granular beds. Physica A, Vol. 247 (1-4), Pp. 67-78.

10. DŽiugys, A. \& Navakas, R., (2007). The role of friction on size segregation of granular materials. Mechanica, Vol. 4 (66), Pp. 59-68.

11. Yan, X., Shi, Q., Hou, M. \& Lu, K., (2003). Effects of air on the segregation of particles in shaken granular bed. Physical Review Letters, Vol. 91 (1), P. (4).

12. MÖbius, M. E., Cheng, X., Eshuis, P., Karczmar, G. S., Nagel, S. R. \& Jaeger, H. M., (2008). The effect of air on granular size separation in a vibrated granular bed. Physical Review E, Vol. 72 (1), Pp. 1-15.

13. Kong, X., Hu, M., Wu, Q. \& Wu, Y., (2006). Effects of vibration frequency on intruders' position in granular bed. Physics Letters A, Vol. 356 (4-5), Pp. 267-271.

14. Ahmad, K., and Smalley, I. J., (1973). Observation of particle segregation in vibrated granular systems. Powder Technology, Vol. 8 (1-2), Pp.69-75.

15. Vanel, L., Rosato, A. D. \& Dave, R. J., (1997). Rise-Time regimes of a large sphere in vibrated bulk solids. Physical Review Letters, Vol. 78 (7), Pp. 1255-1258.

16. Liffman, K., Muriandy, K., Rhodes, M., Gutterridge, D. \& Metcalfe, G., (2001). A segregation mechanism in a vertically shaken bed. Granular Matter, Vol. 3, Pp. 205-214.

17. Trujillo, L. \& Hermann, H. J.,(2003). A note on the upward and downward intruder segregation in granular media. Granular Matter, Vol. 5 (2), Pp.85-89. 